Article

\title{
An Analysis on the Spatial Effect of Absorptive Capacity on Regional Innovation Ability Based on Empirical Research in China
}

\author{
Yingkai Tang ${ }^{1,2}$, Yaozhi Chen ${ }^{2}$, Kun Wang ${ }^{1}\left(\mathbb{D}, \mathrm{He} \mathrm{Xu}^{3, *}\right.$ and Xiaoqi $\mathrm{Yi}^{2}$ \\ 1 The Institute of Financial Studies, Sichuan University, Chengdu 610017, China; tang@scu.edu.cn (Y.T.); \\ liam_wang@stu.scu.edu.cn (K.W.) \\ 2 Business School, Sichuan University, Chengdu 610017, China; chenyz@stu.scu.edu.cn (Y.C.); \\ 2017141063120@stu.scu.edu.cn (X.Y.) \\ 3 Management Science and Engineering School, Central University of Finance and Economics, \\ Beijing 100081, China \\ * Correspondence: 2019110139@email.cufe.edu.cn
}

Received: 2 March 2020; Accepted: 2 April 2020; Published: 9 April 2020

check for updates

\begin{abstract}
Innovation is the primary driving force for development and the core of green, healthy, and sustainable economic development. This paper researches the spatial effect of absorptive capacity on regional innovation capacity from the perspective of knowledge spillover. We use the seven dimensions such as R \& D intensity to build an absorptive capacity index evaluation system. After statistical verification, we select the most suitable empirical model, the dynamic Spatial Durbin Model with two-way fixed effect. The empirical results show that: (1) The promotion effect of absorptive capacity on knowledge spillovers in one province has no obvious effect on innovation promotion in other provinces, especially provinces at similar economic levels. However, it tends to inhibit the innovation development of neighboring provinces. (2) The impact of absorptive capacity on promoting knowledge spillovers varies from region to region. The eastern provinces of China are not affected by the absorptive capacity of neighboring provinces. The regression results of the central and western regions are not substantially different from the full sample. This study puts forward some policy suggestions based on the empirical results. It shows that a higher absorptive capacity does not mean better performance. The Chinese government should thus promote innovation in different provinces according to the local conditions.
\end{abstract}

Keywords: absorptive capacity; knowledge spillover; innovation ability; sustainability; dynamic Spatial Durbin Model

\section{Introduction}

The concept of "sustainable development" was first introduced by World Conservation Strategy in the 1980s. The 1992 Rio Declaration emphasized the goal of maintaining the global environment and achieving sustainable development. There is no doubt that the theme of the 21st century is "sustainable development." It coincides with the general trend of achieving a resource-saving and environmentally friendly development model. With the development of the economy, the role of pure capital accumulation in economic development continues to weaken. In the context of limited resources, the role of return on capital is increasingly prominent. According to the theory of endogenous growth, innovation can not only contribute to sustainable development, but also promote economic growth. Innovation-driven, intensive economic growth has far-reaching significance for building a national innovation system, getting rid of the production mode of high input and low output, and achieving sustainable development. 
Although China has already become the second largest economy in the world, its comprehensive innovation capacity is relatively weak. Up to now, there have been some problems in China's innovation development, such as imbalance and inadequacy. Population and resource mismatches and weak industrial sustainability are already prominent. The Chinese government has given long-term attention and support to innovation development. President Xi Jinping has repeatedly stressed at various conferences that innovation development is urgent. The National Innovation Blue Book: China Innovation Development Report (2016) summarizes the situation: “There are two major constraints on China's innovation development. One is the insufficient use of innovation resources; the other is the insufficient economic transformation rate of innovation results." In view of the above, after consulting the relevant literature, this paper found that the two ratios are closely related to knowledge elements and absorptive capacity. Knowledge is an important factor in innovation development, and its spillover has a significant effect on sustainable economic development [1]. Absorptive capacity also plays a positive role in this process [2]. Nieto and Quevedo emphasized that only when external knowledge is absorbed is the entire spillover process complete. In addition, absorptive capacity is the key to improving spillover efficiency. [3] EgbeTokun and Savin explained that a region with high absorptive capacity can quickly transform received knowledge into expected economic output and realize benefits [4].

Based on the above, this study uses panel data from 30 provinces in China (excluding Hong Kong, Macao, Taiwan, and the Tibet Autonomous Region) from 2006 to 2017 to explore how absorptive capacity promotes knowledge spillover effect to enhance regional innovation capacity. The empirical results show that there is a significant positive spatial autocorrelation in China's regional innovation capabilities (strong or weak agglomeration). The absorptive capacity and knowledge spillover have an insignificant effect on the innovation capacity of other provinces, especially when their economic situation differs. It even has a significantly negative impact on the innovation capacity of neighboring provinces. Furthermore, this study examines the situation in the eastern, central, and western regions of China. The results show that, unlike the central and western regions, the eastern region is not affected.

The contributions of this paper are as follows: First, we use the entropy weight method to construct a seven-dimensional absorptive capacity index, and study it in the same framework as knowledge spillover to comprehensively examine the role of absorptive capacity. Second, the research scope of the previous literature is mostly national. This paper not only analyzes the spatial effect of absorptive capacity on regional innovation capacity at a national level, but also explores the situation in eastern, central, and western China. We extend previous studies with a view to providing advice on innovation policy for local governments. Third, from a review of China's literature on the spatial Dubin model (SDM), we found that most studies directly analyze the coefficients. However, these coefficients are not explanatory [5]. This paper uses more explanatory data-on direct and indirect effects-in the analysis. At the same time, we instituted a series of tests to make the model more rigorous.

The remainder of this paper is organized as follows: In the next section, we review the relevant literature and set out our hypotheses. Section 3 introduces the model, constructs the absorptive capacity and knowledge spillover indexes, deals with endogenous problems that may occur, and selects the weight matrix of the spatial model. Section 4 describes the variables, tests the spatial autocorrelation of China's regional innovation capacity, and quantitatively selects the best model for this study. Section 5 reports and analyzes the empirical results and performs a robustness test. Section 6 summarizes the study.

\section{Literature Review}

\subsection{Absorptive Capacity}

Absorptive capacity was first proposed by Kedia and Bhagat [6]. Cohen and Levinthal define it as the ability of a company to evaluate and absorb external knowledge, and ultimately to commercialize its results [7]. Today, scholars pay more attention to multidimensionality. Chen et al. believe that in the analysis of enterprises, absorptive capacity is the ability of an enterprise to effectively recognize 
and digest new knowledge to commercialize and obtain benefits. From a regional perspective, the absorptive capacity of a region is not only a summary of the capacity of its internal subjects, but also the network role relationship among the innovative subjects [8]. Lau and Lo emphasized that the combination of acquisition, assimilation, transformation, and exploitation in the absorption capacity can explain the entire absorption process [9].

\subsection{Regional Innovation Capability}

Regional innovation capability began with Joseph Alois Schumpeter's “Theory of Economic Development." He believed that innovation was an unprecedented combination of factors and conditions of production. Since Everett M. Rogers and Judith K. Larsen applied the concept of innovation to research at the regional level, the academic community has shifted the focus from national innovation to regional innovation. Regional innovation capability is one aspect of the concept of "innovation." Unless otherwise specified, concepts such as innovation capability and innovation output are generally not distinguished. Weng et al. and Li et al. emphasized that regional innovation capabilities focus on actual results and consider them to be the ability to commercialize knowledge $[10,11]$. Zhang and Chen pointed out that the regional innovation capability is rooted. It achieves sustainable regional development mainly by constructing an innovation exchange network and optimizing resource allocation [12].

\subsection{Knowledge Spillover}

Knowledge spillover originates from the theory of endogenous growth. It is of great significance for research on innovation and economic growth. Unlike knowledge transfer, knowledge spillover focuses on the unconscious transmission of knowledge [13]. Griliches defines knowledge spillover as doing similar things and benefiting from each other [14]. Arrow first stated that knowledge spillover was a key factor in knowledge accumulation [15]. Furthermore, Romer found that the root cause of knowledge spillover is the noncompetitiveness and partial exclusivity of knowledge technology $[16,17]$. Ibrahim and Reilly more accurately describe knowledge spillover as an unconscious act [13]. Bottazzi and Peri point out that the effective range of knowledge spillover is around $300 \mathrm{~km}$ [18]. Breschi and Lissoni put forward the concept of "tacit knowledge" to explain the spatial barriers of spillover effect. That is to say, the knowledge generated in the research process is usually transmitted in the form of "face-to-face communication." Consequently, long-distance overflow cannot be achieved [19]. However, with the improvement of traffic conditions and means of communication, the knowledge spillover effect has gradually surpassed geographical barriers [20]. Earlier studies on knowledge spillovers mostly focused on the enterprise level. However, in 1989, Jaffe incorporated spatial factors into production functions. Since then, scholars have become interested in the regional role of knowledge spillovers [21]. Furthermore, the research by Audretsch and Feldman confirmed that there are obvious externalities between knowledge output and the level of economic activity. The relevant research on knowledge spillovers at the city and regional levels is more significant [22,23].

\subsection{The Role of Absorptive Capacity}

Knowledge spillovers are good for innovation. Cooke found that knowledge spillover can reduce the innovation cost of enterprises. For example, it reduces the uncertainty of innovation [24]. However, there are efficiency issues with spillover effects, which can be alleviated by absorptive capacity. Szulanski found that the main reason for the stickiness of knowledge is the lack of the ability of the receiving subject to absorb the knowledge. This shows that the amount of knowledge actually received by the receiving entity is not only determined by the amount of knowledge available, but also by the absorptive capacity [25]. Chen et al. confirmed that absorptive capacity contributes to the accumulation of knowledge and thus helps to commercialize external knowledge [26]. Tura and Harmaakorpi found that the frequency of communication is positively related to innovation efficiency. The improvement of communication ability will promote the transfer of knowledge among innovation subjects. It also 
greatly reduces the time and capital cost of knowledge transmission [27]. Similarly, Hauser et al. found that interpersonal trust helps with absorbing external knowledge. Newcomers among the innovation subjects will promote exchanges and cooperation between the two parties. Thereby, it will reduce coordination management costs and increase transaction frequency and efficiency [28]. It can be found that "talent" is an important factor for absorptive capacity to work [29]. In China, Wang also proved that talent introduction is important for enterprise innovation and development [30]. Of course, there are exceptions. Agrawal found that the rooted inflow of foreign talent may crowd out existing talent, which may damage the scientific development of the region [31]. In addition, industry-university-research cooperation can also significantly improve the sustainable development and innovation capabilities of enterprises [32,33]. Summarizing the above, it can be seen that absorptive capacity affects innovation capacity by affecting knowledge spillovers. For example, Zhai et al. also indirectly proved this connection, finding that entrepreneurial orientation has significantly positive impacts on enterprise innovation performance, and that absorptive capacity plays a moderating role in the relationship between entrepreneurial orientation and innovation performance [34].

Empirically, absorptive capacity can give full play to the knowledge spillover effect to enhance innovation capacity. Zhang and Zhao tested the impact of the absorptive capacity of technological research and development, human capital, and trade openness on innovation capacity, and found that only some industries benefited from it [35]. Zhang et al. found that, among Shanghai agricultural enterprises, those with higher technology absorptive capacity have faster innovation development and higher innovation output [36]. However, they all consider only the enterprise level, not the regional impact. In addition, they did not consider the role of knowledge spillovers. Although Ma considered the effect of knowledge spillovers, the constructed absorptive capacity indicators were not comprehensive. She did not conduct further research at the subregional level [37].

In fact, absorptive capacity is a double-edged sword. Excessive absorptive capacity may impair innovation. Zhu and Xu empirically found that there is a "double threshold" effect on absorptive capacity, and concluded that there is an "inverted U-shape" relationship between absorptive capacity and regional innovation capacity [38]. Regional technological differences are also important factors affecting the role of absorptive capacity. Jaffe found that, the stronger the technical consistency, the more beneficial it is to enhance regional innovation capabilities [21]. Wei et al. emphasized that too large or too small differences in technological levels are not conducive to the innovation and development of neighboring areas [39]. However, Knag et al. reached the opposite conclusion. They believe that the larger the technological gap is between enterprises, the stronger the willingness there will be to imitate learning, thereby promoting innovation and development [40].

\subsection{Commentary}

By searching the relevant literature, we find that: First, in studying the relationship between absorptive capacity and innovation capacity, most literature ignores the mediating role of knowledge spillover. Second, the literature in China focuses on the role of absorptive capacity at the enterprise level, while ignoring its role at the provincial level. Moreover, few studies have carried out more detailed research at the subregional level. Third, the literature on the conditions of absorptive capacity mostly focuses on technological differences, while few studies have studied factors such as economic and cultural differences. Fourth, in the existing literature in China, most studies incorrectly use the regression coefficients as the basis for analysis, instead of using direct and indirect effects that are truly explanatory. Based on the above and combined with China's reality, this paper proposes the following hypotheses:

Hypothesis 1 (H1): Absorptive capacity inhibits the development of regional innovation capacity in neighboring provinces.

Hypothesis 2 (H2): The greater the regional economic differences, the stronger the role of absorptive capacity in promoting innovation. 


\section{Materials and Methods}

\subsection{Theoretical Model}

The endogenous growth theory holds that the generation of new knowledge stems from the effective use of human and capital factors. Based on the endogenous growth model, this paper uses the Griliches-Jaffe knowledge production function to build a knowledge production model:

$$
P_{i t}=A_{i t} K_{i t}^{\alpha} L_{i t}^{\beta}
$$

where $i$ and $t$ represent the region and time, respectively; $P_{i t}$ represents regional innovation capabilities; $\mathrm{A}_{\text {it }}$ represents the innovation output rate, which is generally constant by default; and $\mathrm{K}_{i t}$ and $\mathrm{L}_{\mathrm{it}}$ represents capital factor input and human factor input, respectively. Since the generation of new knowledge takes time, the $\theta$ phase lag of Equation (1) was performed. Based on past experience, $\theta$ is usually set to 2 .

$$
\mathrm{P}_{\mathrm{i}, \mathrm{t}+\theta}=\mathrm{A}_{\mathrm{it}} \mathrm{K}_{\mathrm{it}}^{\alpha} \mathrm{L}_{\mathrm{it}}^{\beta}
$$

Next, we incorporated factors such as knowledge spillover and absorptive capacity into Equation (2):

$$
\mathrm{P}_{\mathrm{i}, \mathrm{t}+\theta}=\mathrm{A}_{\mathrm{it}} \mathrm{K}_{\mathrm{it}}^{\alpha} \mathrm{L}_{\mathrm{it}}^{\beta} \mathrm{KS}_{\mathrm{it}}^{\gamma} \mathrm{AB}_{\mathrm{it}}^{\tau} \mathrm{C}_{\mathrm{it}}^{\lambda} \text {, }
$$

where $\mathrm{KS}_{\mathrm{it}}$ represents knowledge spillover; $\mathrm{AB}_{\mathrm{it}}$ represents absorptive capability; and $\mathrm{C}_{\mathrm{it}}$ represents other factor inputs, that is, control variables. $\alpha, \beta, \gamma, \tau$, and $\lambda$ represent the output elasticity of each corresponding variable. Next, we performed logarithmic processing on Equation (3). We transformed the model into a linear equation to alleviate potential heteroscedasticity problems.

$$
\begin{aligned}
& \ln \mathrm{P}_{\mathrm{i}, \mathrm{t}+\theta}=\varphi+\alpha \ln \mathrm{K}_{\mathrm{it}}+\beta \ln \mathrm{L}_{\mathrm{it}}+\gamma \ln \mathrm{KS}_{\mathrm{it}}+\tau \ln \mathrm{AB}_{\mathrm{it}}+\lambda \ln \mathrm{C}_{\mathrm{it}} \\
& \text { s.t. } \varphi=\ln \mathrm{A}_{\mathrm{it}}
\end{aligned}
$$

Absorptive capacity indicators contain human factors. In order to avoid unnecessary errors caused by repeated indicators, we removed the $\ln \mathrm{L}_{\mathrm{it}}$ variable. At the same time, the provincial panel data usually have two-way fixed effects that change with changes in space and time. Considering this, we added intercept variable $u_{i}$, representing the spatial fixed effect, and intercept variable $v_{t}$, representing the time fixed effect. In addition to the variables mentioned, there are many factors that have a weak impact on regional innovation capabilities. This study summarizes them as random disturbance terms $\varepsilon_{i, t+\theta}$. Based on the above, this paper improves Equation (4) to create a model with two-way fixed effects (Equation (5)):

$$
\begin{array}{r}
\ln \mathrm{P}_{\mathrm{i}, \mathrm{t}+\theta}=\varphi+\alpha \ln \mathrm{K}_{\mathrm{it}}+\gamma \ln \mathrm{KS}_{\mathrm{it}}+\tau \ln \mathrm{AB}_{\mathrm{it}}+\lambda \ln \mathrm{C}_{\mathrm{it}}+\mathrm{u}_{\mathrm{i}}+\mathrm{v}_{\mathrm{t}}+\varepsilon_{\mathrm{i}, \mathrm{t}+\theta} \\
\varepsilon_{\mathrm{i}, \mathrm{t}+\theta} \sim \mathrm{N}\left(0, \sigma^{2} \mathrm{I}_{\mathrm{n}}\right)
\end{array} .
$$

In order to study the promoting effect of absorptive capacity on knowledge spillover effect, this paper adds the interaction term of absorptive capacity and knowledge spillover, $\ln \mathrm{AB}_{\mathrm{it}} * \ln \mathrm{KS}_{\mathrm{it}}$, based on Equation (5):

$$
\begin{aligned}
& \ln \mathrm{P}_{\mathrm{i}, \mathrm{t}+\theta}=\varphi+\alpha \ln \mathrm{K}_{\mathrm{it}}+\gamma \ln \mathrm{KS}_{\mathrm{it}}+\tau \ln \mathrm{AB}_{\mathrm{it}}+\omega\left(\ln \mathrm{AB}_{\mathrm{it}} * \ln \mathrm{KS}_{\mathrm{it}}\right) \\
& +\lambda \ln \mathrm{C}_{\mathrm{it}}+\mathrm{u}_{\mathrm{i}}+\mathrm{v}_{\mathrm{t}}+\varepsilon_{\mathrm{i}, \mathrm{t}+\theta}
\end{aligned}
$$

\subsection{Empirical Model Construction}

In China, no province is completely isolated from the outside world. Cooperation and exchange between provinces will inevitably produce spatial effects. Common spatial models include the spatial lag model (SLM), the spatial error model (SEM), and the spatial Durbin model (SDM). SLM uses 
a combination of space factor and the lagging term of the explanatory variable $\mathrm{WlnP}_{\mathrm{t}+\boldsymbol{\theta}}$ as the explanatory variable. These reflect the influence of the individual on other individuals in the system. SEM assumes that the disturbance term is spatially dependent, that is, $\mu=\rho \mathrm{M} \mu+\zeta, \zeta \sim \mathrm{N}\left(0, \sigma^{2} \mathrm{I}_{n}\right)$. This indicates that there are spatial correlations between missing variables or unobservable random shocks. SDM uses the combination of spatial factors and explanatory variables $W X$ and $W \ln P_{t+\theta}$ as explanatory variables. These reflect the interaction between individuals and other individuals in the system. As a rule of thumb, spatial Durbin models are often more applicable. Therefore, in this paper, the ordinary panel model is improved to create the spatial Durbin model according to Equation (6):

$$
\begin{aligned}
& \ln \mathrm{P}_{\mathrm{i}, \mathrm{t}+\theta}=\alpha \ln \mathrm{K}_{\mathrm{it}}+\gamma \ln \mathrm{KS}_{\mathrm{it}}+\tau \ln \mathrm{AB}_{\mathrm{it}}+\lambda \ln \mathrm{C}_{\mathrm{it}} \\
& +\omega\left(\ln \mathrm{AB} \text { it } \times \ln \mathrm{KS}_{\mathrm{it}}\right)+\rho \mathrm{W} \ln \mathrm{P}_{\mathrm{i}, \mathrm{t}+\theta}+\chi_{1} \mathrm{~W} \ln \mathrm{K}_{\mathrm{it}} \\
& +\chi_{2} \mathrm{~W} \ln \mathrm{KS}_{\mathrm{it}}+\chi_{3} \mathrm{~W} \ln \mathrm{AB}_{\mathrm{it}}+\chi_{4} \mathrm{~W} \ln \mathrm{C}_{\mathrm{it}} \\
& +\chi_{5} \mathrm{~W}\left(\ln \mathrm{AB}_{\mathrm{it}} * \ln \mathrm{KS}_{\mathrm{it}}\right)+\mu_{\mathrm{i}}+\mathrm{v}_{\mathrm{t}}+\varepsilon_{\mathrm{i}_{1}+\theta}
\end{aligned}
$$

\subsection{Measure of Absorptive Capacity}

\subsubsection{Construction of Absorptive Capacity}

Based on the existing literature, this paper adjusted the seven-dimensional index evaluation system of absorptive capacity as follows:

$\mathrm{R} \& \mathrm{D}$ capabilities. The carrier of knowledge generation is people. The research and development capabilities are the core of new knowledge generation. In addition, they are closely related to the ability of companies in the region to digest and apply existing knowledge. In other words, improving $\mathrm{R} \& \mathrm{D}$ capabilities will help the region acquire external knowledge and increase positive externalities.

Economic level. This reflects the prosperity of a region. For most people, wages and benefits are among the important considerations in career choice and planning. Generally, economically developed regions (such as Beijing, Shanghai, and Shenzhen) offer higher wages and more benefits and employment opportunities. Therefore, the economic level is one of the key factors for encouraging innovative talents; it is also an important component of absorbing capacity.

Human capital. This directly affects a region's ability to imitate and absorb new knowledge, especially tacit knowledge. It is one of the important channels for knowledge spillovers. Abundant human capital can enhance the frequency and efficiency of knowledge exchange. It can expand the breadth and depth of knowledge exchange, and it is also an integral part of absorptive capacity.

Openness. This mainly refers to the degree of opening to the outside world, that is, the degree of interaction between a region and foreign enterprises. It is related to the ability of enterprises to learn advanced foreign knowledge. Trading with excellent foreign manufacturers is more conducive to accumulating experience for regional companies. In this way, companies can absorb advanced knowledge and technology, and learn from each other. Therefore, the degree of openness is one of the important dimensions of absorptive capacity.

Infrastructure. Economically developed regions will attract more talent. Similarly, a beautiful environment and sound infrastructure are also important considerations when choosing a career. In particular, when a person's salary rises to a certain level, his or her requirements for the quality of life will obviously increase. In reality, such high-wage people are often the main force of innovation. Therefore, infrastructure construction is of great significance to innovation and is an important part of absorptive capacity.

Way of spreading. Early research shows that the spillover effect of knowledge is limited by geographic distance. The farther apart two places are, the more difficult it is for them to communicate knowledge. Rich and perfect transmission channels can greatly weaken the constraints of geographical distance. They can enhance the effective range of spillover effects and promote the absorption of external knowledge in various regions. Therefore, the transmission route is an important component of absorptive capacity. 
Government governance. Wang and Hu found that the venture capital investment of state-owned enterprises to promote innovation is significantly weaker than that of non-state-owned ones [41]. In China, we found that government $\mathrm{R} \& \mathrm{D}$ investment is negatively related to the technology market transaction value. There are "offside," "absence," and "dislocation" in government support measures. That is to say, it is difficult for the government's innovation investment to effectively flow into small and medium-sized enterprises, which lack sufficient funds. In a freely competitive market, funds will flow automatically toward companies with investment value under the guidance of "invisible acceptance." This promotes exchanges between enterprises and enhances their innovation capabilities. Therefore, this study treats government governance as part of absorptive capacity.

\subsubsection{Description of Secondary Indicators of Absorptive Capacity}

Based on the seven dimensions of the absorptive capacity index evaluation system, this paper selects 14 representative secondary indicators from the China Statistical Yearbook, China Statistical Yearbook on Science and Technology, Provincial Statistical Yearbook, etc., as shown in Table 1. They are as follows:

Table 1. Absorptive capacity index evaluation system.

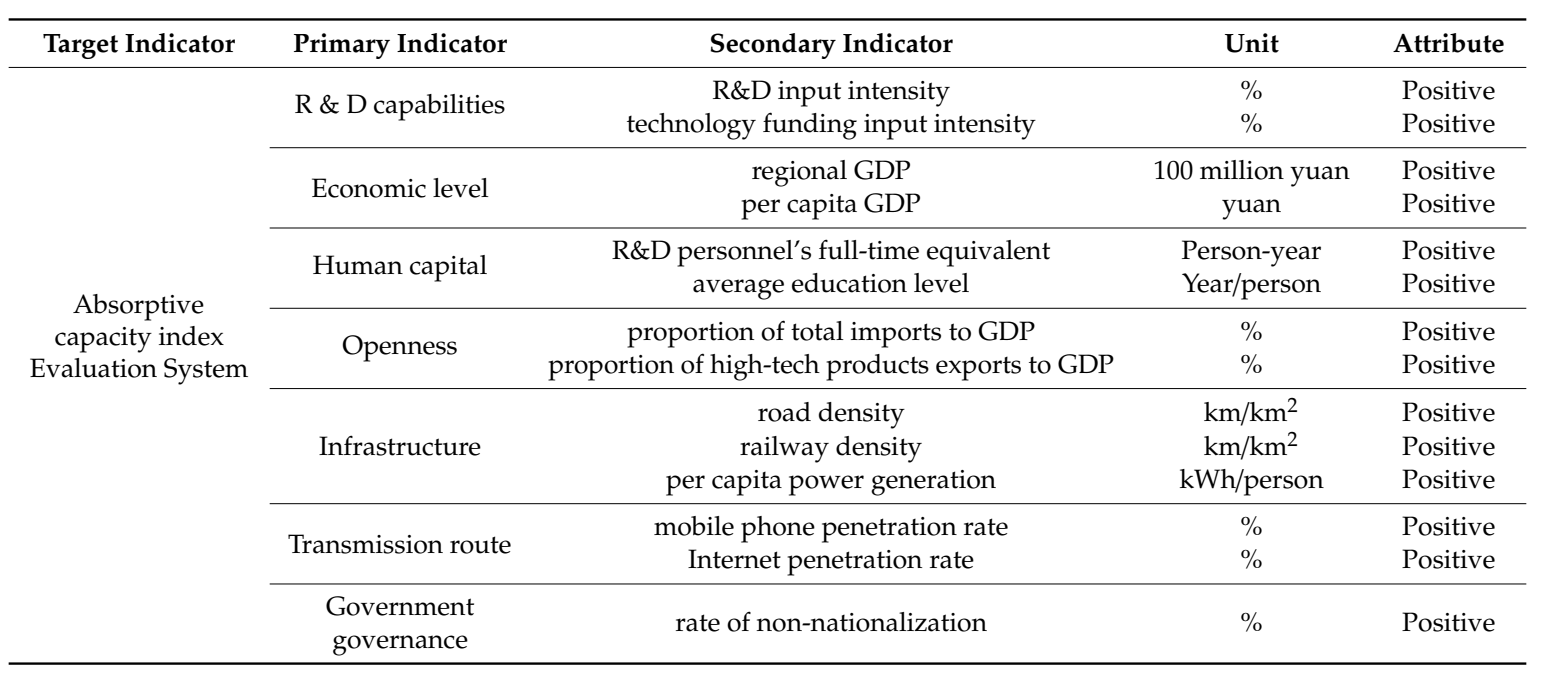

Dimensions of R \& D intensity, using traditional indicators, namely R \& D input intensity (unit: \%) and scientific and technological expenditure input intensity (unit: \%). These are calculated by dividing the regional $R$ \& D expenditure and the general public budget expenditure of science and technology by the regional GDP.

The economic level is measured by the two most direct and generally accepted indicators: regional GDP (unit: billion yuan) and per capita GDP (unit: yuan). Regional GDP measures the overall economic level of the region. GDP per capita includes regional size and general economic level.

Human capital dimension, measured by R \& D personnel full-time equivalent (unit: person-year) and average education level (unit: year/person). The R \& D personnel's full-time equivalent is obtained from the existing data in the China Science and Technology Statistics Yearbook. This study calculates the average education level according to the current Chinese academic year system. The specific calculation formula is as follows: Average education level $=$ (proportion of junior college or above $* 16+$ proportion of high school $* 12+$ proportion of junior high school $* 9+$ proportion of primary school $* 6$ )/ number of persons over 6 years of age.

The degree of openness is measured by the proportion of total imports in GDP (unit: \%) and the proportion of high-tech product exports in GDP (unit: \%). Imported goods and high-tech products often have advantages that are worth considering. Through long-term contact, companies will subtly improve their own understanding of the product and then enhance their absorption capacity. 
In terms of infrastructure, Zhao and Bi found that high-speed rail can promote labor mobility. This in turn promotes knowledge spillover effects [42]. Therefore, we use the road density (unit: $\mathrm{km} / \mathrm{km}^{2}$ ) and railway density (unit: $\mathrm{km} / \mathrm{km}^{2}$ ) to reflect the level of regional transportation facilities. Moreover, we use the per capita power generation ( $\mathrm{kWh} /$ person or degree/person) to reflect the quality of life of people in the region. The two density indicators are the corresponding mileage and the proportion of the land area. The per capita power generation is calculated by dividing the regional power generation by the total population at the end of the year.

Dimensions of transmission channels. These are measured by the mobile phone penetration rate (unit: \%) and Internet penetration rate (unit: \%). Mobile phones and the Internet have facilitated exchanges between innovation subjects. Both are calculated by dividing the corresponding number of local users by the total population at the end of the year.

The dimension of government governance is measured by the denationalization rate (unit: \%), that is, the denationalization rate $=1-$ total industrial output value of state-owned enterprises/industrial output value of enterprises above a designated size.

\subsubsection{Entropy Weight Method and Weight Determination Method}

"Entropy" is derived from thermodynamics, indicating the uncertainty (degree of dispersion) of things. The greater the degree of dispersion of each secondary indicator in the indicator system, the greater the amount of effective information it contains, and the higher the weight. The entropy method has the advantages of alleviating the consistency of indicators, giving weight objectively, and reducing the overlap of multi-index information. Therefore, this paper uses the entropy method to give weight to each secondary index of absorption capacity. The basic principle of the entropy method is as follows:

First, we establish an index system matrix. Assuming that there are $m$ samples in each of k periods, and the indicator system consists of $\mathrm{n}$ secondary indicators, the indicator system matrix is:

$$
A_{t}=\left(a_{i j, t}\right)_{\mathrm{m} \times \mathrm{n}}(i=1, \cdots, m j=1, \cdots, n t=1, \cdots, k)
$$

In Equation (8), the $a_{i j, t}$ factor of the sample $i$ in the $t$-th period is expressed. In order to eliminate the influence of the dimensions between the indicators, matrix $A_{t}$ is standardized, and the standardized matrix of each indicator is obtained.

Secondly, due to the dimensional problem in $a_{i j, t}$, this paper uses the " $0-1$ normalization method" to process the data. Considering that the "0-1 normalization method" will lead to 0 in the standardized data and each secondary index is a positive indicator, we use an improved positive " $0-1$ normalization method." Let the normalized matrix be $A=\left(a_{i j}\right)_{\mathrm{m} \times \mathrm{n}}$ and the coefficient $\mathrm{U}$ be 1 to obtain the result before the improvement method. The constant $\mathrm{D}$ is 1 to solve the situation where the value is 0 . The specific formula is:

$$
a_{i j}=U \times \frac{a_{i j}-\min _{j}\left|a_{i j}\right|}{\max _{j}\left|a_{i j}\right|-\min _{j}\left|a_{i j}\right|}+D
$$

After normalizing the statistical values, the information entropy can be calculated:

$$
E_{i}=-\ln (n)^{-1} \sum_{i=1}^{n} p_{i j} \ln p_{i j}
$$

where $\mathrm{p}_{\mathrm{ij}}=\mathrm{a} / \sum_{\mathrm{i}=1}^{\mathrm{n}} \mathrm{a}_{\mathrm{ij}}$. If $\mathrm{p}_{\mathrm{ij}}=0, \lim _{\mathrm{p}_{\mathrm{ij}} \rightarrow 0} \mathrm{p}_{\mathrm{ij}} \ln \mathrm{p}_{\mathrm{ij}}=0$.

Finally, the weight of each indicator is calculated by the information entropy of each indicator. The formula is as follows:

$$
\text { Weight }_{\mathrm{i}}=\frac{1-\mathrm{E}_{\mathrm{i}}}{\mathrm{m}-\sum \mathrm{E}_{\mathrm{i}}}(\mathrm{i}=1, \cdots, \mathrm{m})
$$




\subsection{Knowledge Spillover Measure}

Based on the perspectives of $\mathrm{Xu}$ et al., this paper uses the economic distance matrix [43] to weight the R \& D capital stock in other regions outside the region, so it reflects the level of knowledge spillovers that may be obtained in the region. The specific formula is as follows:

$$
\begin{gathered}
\mathrm{KS}_{\mathrm{it}}=\sum_{\mathrm{j} \neq \mathrm{i}, \mathrm{j}=1}^{\mathrm{N}=30} \mathrm{~W}_{\mathrm{ij}} \times \mathrm{K}_{\mathrm{jt}}^{\prime} \\
\mathrm{W}_{1, \mathrm{ij}}=\frac{1}{\left|\mathrm{Y}_{\mathrm{i}}-\mathrm{Y}_{\mathrm{j}}\right|^{\prime}}
\end{gathered}
$$

where $i$ and $j$ represent regions. $K S_{i t}$ represents the period. $K S_{i t}$ is knowledge spillover level. $W_{i j}$ is the economic distance matrix. $Y_{i}$ represents the average GDP per capita in area i from 2006 to 2017. $\mathrm{K}_{\mathrm{jt}}^{\prime}$ represents R \& D capital stock.

Regarding R \& D capital stock, this paper uses the perpetual inventory method $[14,44,45]$. The formula is as follows:

$$
\mathrm{K}_{\mathrm{jt}}^{\prime}=\mathrm{E}_{\mathrm{j}, \mathrm{t}-1}+(1-\delta) \mathrm{K}_{\mathrm{j}, \mathrm{t}-1}^{\prime}
$$

where $E_{j, t-1}$, measured by the internal expenditure of $R \& D$, is the capital flow of $R \& D ; \delta$ represents the depreciation rate of capital. Based on past experience, it is set to $15 \%$ [44,45]. Assuming that the average annual growth rate of the capital stock is equal to the average annual growth rate of its flows, we use Equations (15) and (16) to estimate the R \& D stock in the base period:

$$
\frac{K_{j t}^{\prime}-K_{j, t-1}^{\prime}}{K_{j, t-1}^{\prime}}=\frac{E_{j t}-E_{j, t-1}}{E_{j, t-1}}=\bar{g}
$$

When $\mathrm{t}=1$, we have:

$$
K_{j 0}^{\prime}=\frac{E_{j 0}}{g+\delta}
$$

where $\bar{g}$ represents the average growth rate of $R \& D$ capital. This study uses the arithmetic average growth rate of $R$ \& D internal expenditures from 2006 to 2017. $E_{j 0}$ and $K_{j 0}^{\prime}$ represent the $R$ \& D internal expenditures and the stock of $\mathrm{R} \& \mathrm{D}$ in the base period.

In addition, we replace the economic distance matrix with the freight rail mileage matrix. We establish a new knowledge spillover variable to test the robustness of the empirical results:

$$
\mathrm{W}_{2, \mathrm{ij}}=\frac{1}{\mathrm{D}_{\mathrm{ij}}}
$$

where $\mathrm{D}$ is calculated by using the provincial capital city freight railway time. When there are two or more paths, take the shortest one.

\subsection{Endogenous Improvement}

$$
\begin{aligned}
& \ln \mathrm{P}_{\mathrm{i}, \mathrm{t}+\theta}=\alpha \ln \mathrm{K}_{\mathrm{it}}+\gamma \ln \mathrm{KS}_{\mathrm{it}}+\tau \ln \mathrm{AB}_{\mathrm{it}}+\lambda \ln \mathrm{C}_{\mathrm{it}}+\kappa \ln \mathrm{P}_{\mathrm{i}, \mathrm{t}+\theta} \\
& +\omega\left(\ln \mathrm{AB}_{\mathrm{it}} \times \ln \mathrm{KS}_{\mathrm{it}}\right)+\rho \mathrm{W} \ln \mathrm{P}_{\mathrm{i}, \mathrm{t}+\theta}+\chi_{1} \mathrm{~W} \ln \mathrm{K}_{\mathrm{it}} \\
& +\chi_{2} \mathrm{~W} \ln \mathrm{KS}_{\mathrm{it}}+\chi_{3} \mathrm{~W} \ln \mathrm{AB}_{\mathrm{it}}+\chi_{4} \mathrm{~W} \ln \mathrm{C}_{\mathrm{it}}+\chi_{5} \mathrm{~W} \ln \mathrm{P}_{\mathrm{i}, \mathrm{t}+\theta} \\
& +\chi_{6} \mathrm{~W}\left(\ln \mathrm{AB}_{\mathrm{it}} * \ln \mathrm{KS}_{\mathrm{it}}\right)+\mu_{\mathrm{i}}+\mathrm{v}_{\mathrm{t}}+\varepsilon_{\mathrm{i}, \mathrm{t}+\theta}
\end{aligned}
$$

This study analyzes the possible endogenous problems of the model as follows:

There are generally three causes of endogeny: variable measurement errors (not considered here because they cannot be processed), missing important explanatory variables, and a two-way 
causal relationship between the explanatory variables and the explained variables. In the spatial Durbin model, it can be considered that the variable $W \ln P_{\mathrm{t}+\theta}$, consisting of the explanatory variable and the spatial factor, contains the missing variables that originally existed in the disturbance term. Consequently, it is considered that there is no endogenous problem caused by the missing variables. There may be endogenous problems in the model due to the causal relationship between absorptive capacity and regional innovation capacity. Considering this, we introduce a lagging explanatory variable, $\ln P_{i, t+\theta-1}$, to construct a dynamic spatial Durbin model. In this way, we can alleviate the bidirectional causality endogeny.

\subsection{Spatial Weight Matrix Selection}

The spatial weight matrix can reflect the specific spatial relationship between regions. It is an essential part of the spatial econometric model. Common spatial weight matrices have a first-order adjacency matrix, a geographical distance matrix, and an economic distance matrix. Considering the relationships among Chinese provincial regions and the rapid development of China's transportation and communications, we decided to use the first-order adjacency matrix as the spatial weight matrix. Equation (19) is the formula for the construction of the first-order adjacency matrix:

$$
\mathrm{W}_{\mathrm{ij}}=\left\{\begin{array}{ll}
1 & \text { Province I is adjacent to province } \mathrm{J} \\
0 & \text { Otherwise }
\end{array} .\right.
$$

If two provinces are next to each other, assign 1; otherwise, assign 0 . Based on the particularity of China's geographic location, although Hainan Province, Guangdong Province, and Guangxi Zhuang Autonomous Region face each other across the sea, they still have an adjacent relationship by default. Consequently, we assign a value of 1 .

\section{Results and Discussion}

\subsection{Variable Description}

\subsubsection{Explained Variable}

The explanatory variable is the regional innovation capacity $(\mathrm{P})$. Regional innovation capability can be a comprehensive indicator or a single indicator. In terms of comprehensive indicators, Guan and Ma defined innovation capabilities from seven levels: resource development capabilities, strategic capabilities, learning capabilities, research and development capabilities, manufacturing capabilities, marketing capabilities, and organizational capabilities [46]. In terms of a single indicator, patent data are a good substitute variable. The biggest advantage is that they are closely related to the company's research and development process and the data are complete and easy to obtain [47-49]. In China, scholars often use the number of patent grants as a proxy for regional innovation capabilities [37]. Due to the comprehensive consideration of absorptive capacity, some of the indicators may overlap with the regional innovation capacity indicators, which is constructed by the comprehensive indicator method. In order to avoid unnecessary errors such as endogeny and multicollinearity, we decided to use the amounts of patents granted per 10,000 as a proxy for regional innovation capabilities.

\subsubsection{Explanatory Variables}

Explanatory variables include capital stock (K), knowledge spillovers (KS), absorptive capacity $(\mathrm{AB})$, and interaction terms of knowledge spillover and absorptive capacity (ABKS).

The capital stock is obtained by processing the internal expenditure of $\mathrm{R} \& \mathrm{D}$ through the perpetual inventory method, which is described in detail in Section 3.4.

The absorptive capacity is composed of 14 indicators in seven dimensions. This study uses the entropy weight method to weight each secondary indicator to calculate the score. The process was described in detail in Section 3.3. We used Matlab R2016a (Matchworks, Natick, MA, USA) to perform 
calculations to get the weight of each secondary indicator of absorption capacity, as shown in Table 2 (due to the length of the chart, only some years are listed). At the same time, we draw a bar chart of its average weight from 2006 to 2017 (Figure 1), making the conclusion more intuitive. It can be found that the ranking of each indicator is relatively stable. they are: railway density, highway density, R \& D funding input intensity, the proportion of imported products in GDP, the proportion of high-tech product exports in GDP, and the weight of $\mathrm{R} \& \mathrm{D}$ personnel's full-time equivalent rank in the forefront (n no particular order; the same applies hereinafter). Conversely, the mobile phone penetration rate, Internet penetration rate, and per capita power generation have always been at the bottom. In numerical terms, the weights of the indicators have not fluctuated greatly over the years. There have been no extremely high indicators. It is numerically shown that each index is significant.

Table 2. Absorptive capacity of each secondary indicator weight.

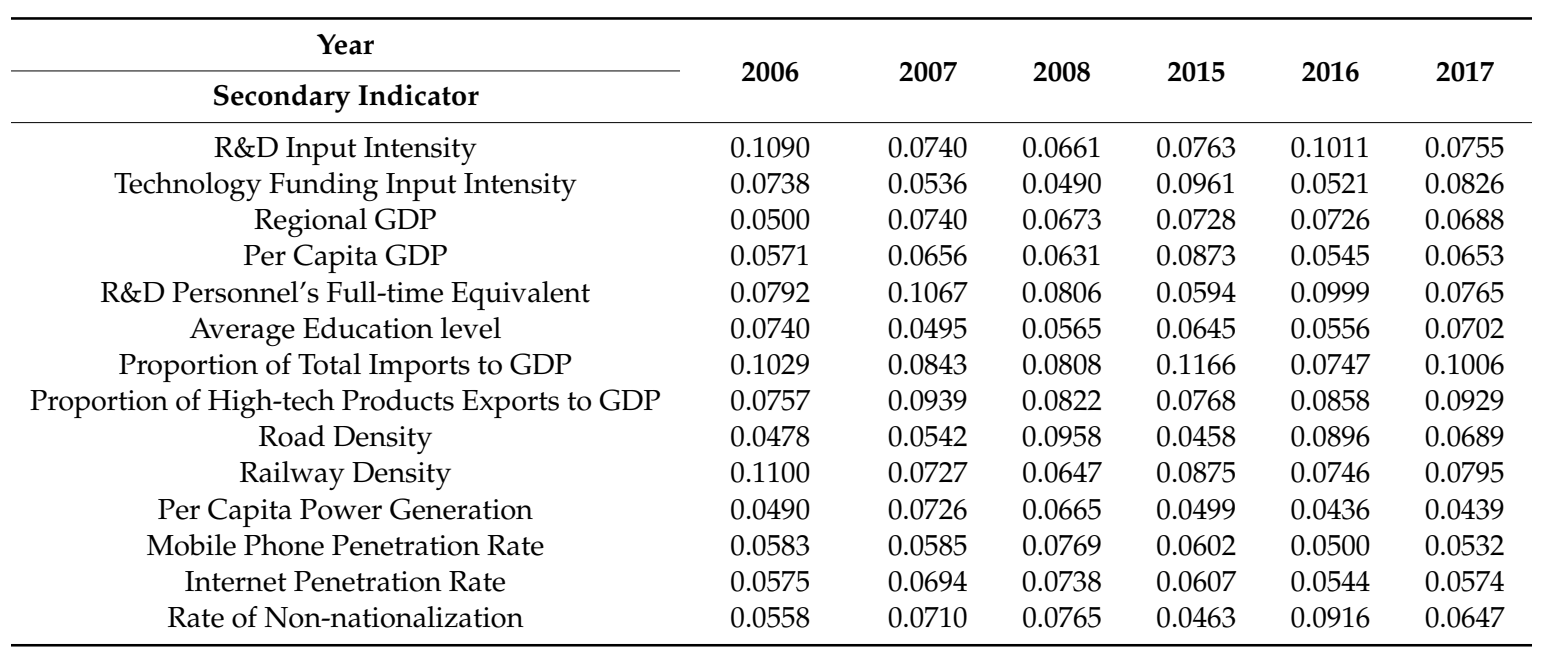

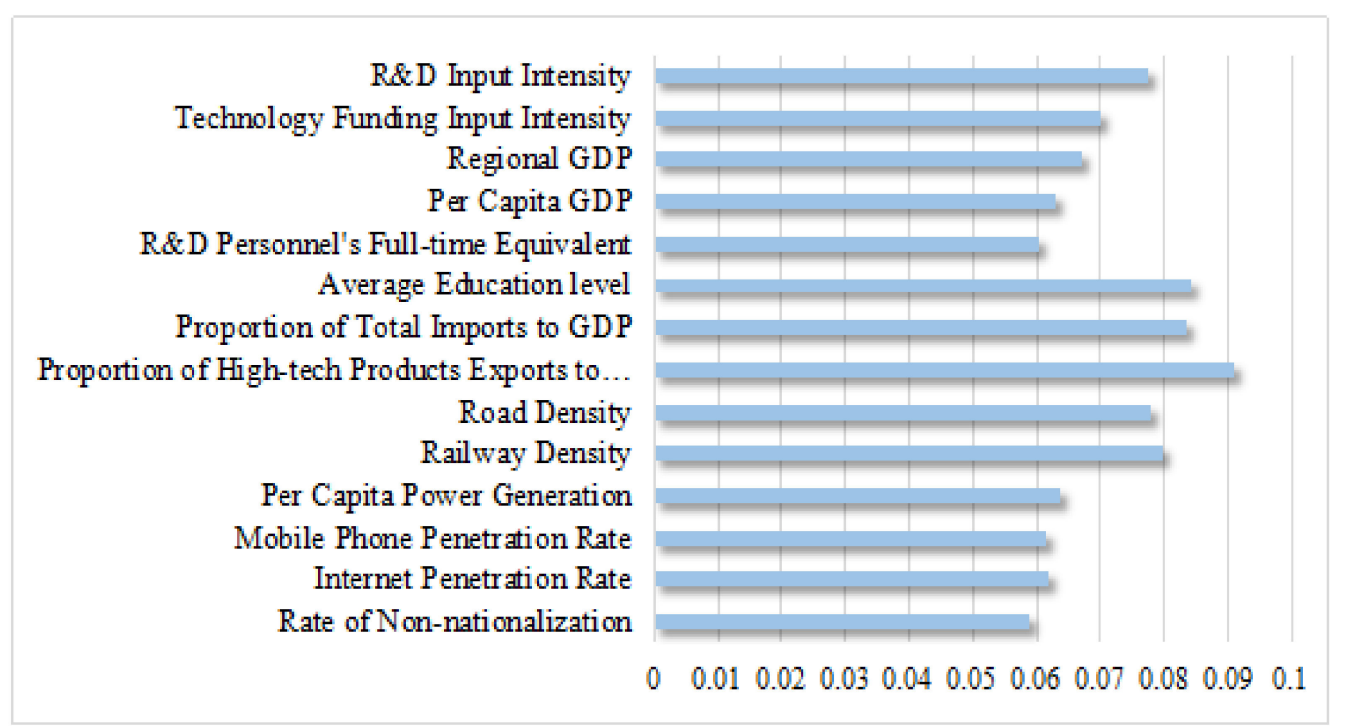

Figure 1. Average weight of each index of absorptive capacity.

The knowledge spillover is composed of R \& D capital stock and an economic distance spatial weight matrix. Section 3.4 describes the measurement process in detail. Figure 2 shows a comparison of the average knowledge spillover effects experienced by the provinces from 2006 to 2016. According to Figure 2, Fujian, Tianjin, Shanghai, Inner Mongolia, Liaoning, and other places have strong knowledge spillover effects, followed by Shandong, Jiangsu, Beijing, Zhejiang, and other places, while the remaining provinces have maintained a low level. 


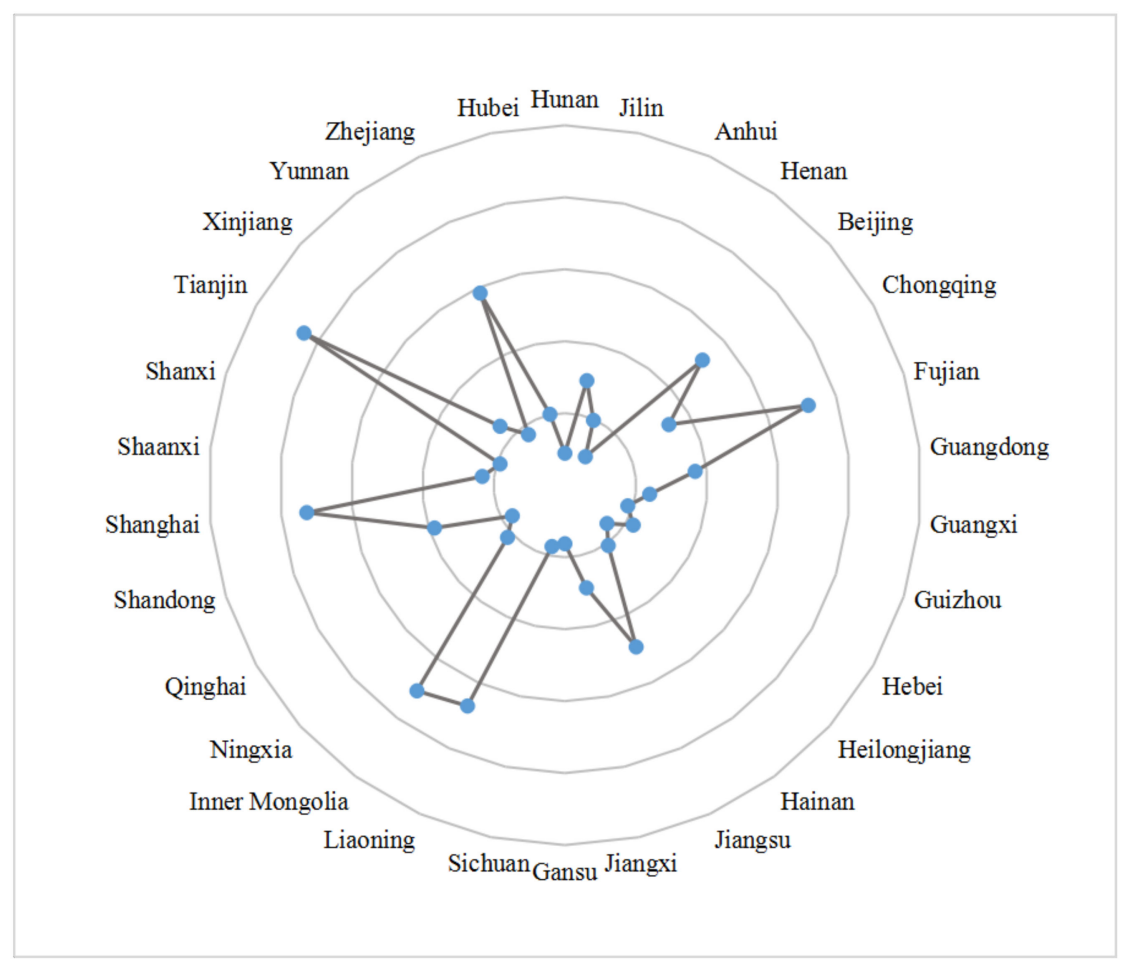

Figure 2. Distribution of the average knowledge spillover effect in each province in 2006-2016.

The absorptive capacity is composed of 14 indicators in seven dimensions. The score is calculated by the entropy weight method. We describe the process in detail in Section 3.3.

\subsubsection{Control Variable}

Because the absorptive capacity index evaluation system covers a wide range, there is no need to use too many control variables. Foreign direct investment (FDI) includes tangible and intangible investments. FDI, especially the intangible investment part, plays an important role in the innovation of the investee. Chen has empirically found that the FDI channel has a significant promoting effect on international R \& D spillover effects. He pointed out that this conclusion is more applicable to countries in transition and developing [50]. Considering that the scope of this study is limited to China, which is a developing country, the amount of foreign direct investment (unit: 10,000 U.S. dollars) is used as a control variable. It can mitigate the factors affecting innovation from abroad.

All data in this study were compiled from the China Statistical Yearbook, China Statistical Yearbook on Science and technology, Provincial Statistical Yearbook, etc. In view of the completeness and availability, this study selects the annual data of 30 provincial units in China (excluding Hong Kong, Macao and Taiwan regions, Tibet Autonomous Region) from 2006 to 2017. If the statistical caliber is inconsistent, the China Statistical Yearbook on Science and Technology shall prevail. Descriptive statistics of each variable are given in Table 3.

Table 3. Descriptive statistics.

\begin{tabular}{ccccc}
\hline Variable & Means & Standard Deviation & Maximum & Minimum \\
\hline $\mathrm{P}$ & 8.820 & $1.494 \times 10$ & $1.315 \times 10^{2}$ & $4.000 \times 10^{-2}$ \\
$\mathrm{~K}$ & $2.966 \times 10^{6}$ & $3.789 \times 10^{6}$ & $2.036 \times 10^{7}$ & $2.104 \times 10^{4}$ \\
$\mathrm{KS}$ & $9.266 \times 10^{6}$ & $8.427 \times 10^{6}$ & $4.271 \times 10^{7}$ & $6.646 \times 10^{5}$ \\
$\mathrm{AB}$ & $3.420 \times 10^{-2}$ & $5.510 \times 10^{-3}$ & $4.509 \times 10^{-2}$ & $2.368 \times 10^{-2}$ \\
$\mathrm{FDI}$ & $6.648 \times 10^{5}$ & $7.234 \times 10^{5}$ & $3.576 \times 10^{6}$ & $1.414 \times 10^{3}$ \\
\hline
\end{tabular}




\subsection{Spatial Autocorrelation Analysis}

Tobler once said, "Everything is related to everything else, but near things are more related than distant things." [51] This view is called "the first law of geography." It is one of the basic theories of spatial econometrics. Spatial autocorrelation analysis is the premise of using spatial econometric models. The spatial autocorrelation test of the interpreted variables (regional innovation capabilities) can determine its spatial distribution characteristics. If the regional innovation capability exhibits a random distribution, it is not necessary to use a spatial measurement method. If it exhibits the characteristics of spatial agglomeration, we use the spatial measurement method. This study selects the first-order adjacency matrix as the model's spatial weight matrix. Consequently, we use the first-order adjacency matrix to perform spatial autocorrelation analysis on regional innovation capabilities.

\subsubsection{Full Spatial Autocorrelation Analysis}

Global spatial autocorrelation analysis mainly examines the spatial agglomeration of the entire spatial sequence. A commonly used test method is the Moran's I test. The value range of Moran's I is $[-1,1]$. When the value is greater than 0 , it indicates that there is a positive spatial autocorrelation. When the value is less than 0 , it indicates that there is a negative spatial autocorrelation. When the value is 0 , it indicates that it is not. There is spatial autocorrelation. The specific formula is as follows:

$$
I=\frac{\sum_{i=1}^{n} \sum_{j=1}^{n} w_{i j}\left(x_{i}-\bar{x}\right)\left(x_{j}-\bar{x}\right)}{S^{2} \sum_{i=1}^{n} \sum_{j=1}^{n} w_{i j}}
$$

where $S^{2}=\frac{\sum_{i=1}^{n}\left(x_{i}-\bar{x}\right)}{n}$ is the sample variance and $w_{i j}$ is the spatial weight matrix element; $\mathrm{n}$ is the sample capacity, that is, the number of regions studied; $x_{i}$ and $x_{j}$ represent the attributes of $\mathrm{i}$ and $\mathrm{j}$ regions, that is, regional innovation capabilities; and $\bar{x}=\frac{1}{n} \sum_{i=1}^{n} x_{i}$, which is the mean of $x_{i}$.

Using StataSE 15 (StataCorp, 4905 Lakeway Drive College Station, Texas, 77845, USA), we select the first-order adjacency data and regional innovation capability data of 30 provincial regions in China to calculate the Moran's I Index of China's regional innovation capabilities from 2006 to 2017, as shown in Table 4. The Moran's I values of all years are greater than 0 and have passed a significance test of at least $5 \%$. This indicates that China's regional innovation capability has significant positive spatial autocorrelation and obvious spatial agglomeration. Consequently, we should use spatial measurement methods.

Table 4. Moran' s I (2006-2017).

\begin{tabular}{ccc}
\hline Year & Moran's I & $p$-Value \\
\hline 2006 & 0.263 & 0.004 \\
2007 & 0.273 & 0.005 \\
2008 & 0.286 & 0.006 \\
2009 & 0.264 & 0.023 \\
2010 & 0.251 & 0.031 \\
2011 & 0.183 & 0.027 \\
2012 & 0.187 & 0.014 \\
2013 & 0.194 & 0.024 \\
2014 & 0.195 & 0.033 \\
2015 & 0.200 & 0.034 \\
2016 & 0.194 & 0.038 \\
2017 & 0.206 & 0.013 \\
\hline
\end{tabular}


The Moran's I index of China's regional innovation capabilities over the years is positive in value. This indicates that there is a positive spatial autocorrelation. In addition, the data of all years have passed at least a 5\% significance test, rejecting the null hypothesis that "there is no spatial autocorrelation." This indicates that there is a significant positive spatial autocorrelation in regional innovation output over the years. The phenomenon of agglomeration is more obvious.

\subsubsection{Local Spatial Autocorrelation Analysis}

Global space autocorrelation can verify the existence and type of spatial autocorrelation. However, there are two cases of positive space autocorrelation: high-value clustering, and low-value clustering. Moran's I scatter plots are needed to investigate. The Moran's I scatter plot is established in a standardized Cartesian coordinate system. The abscissa reflects the attributes of the local area. The ordinate reflects the average of the attributes of adjacent areas. There are four quadrants in the Moran's I scatterplot. The first quadrant (HH) represents high-value clustering, also called Hot Spot. The third quadrant (LL) represents low-value clusters, also known as Cold Spot. If the data have a positive spatial autocorrelation, the type of aggregation can be further judged by the distribution of the first and third quadrants. In the same way, the second quadrant (LH) and the third quadrant (HL) can help determine the aggregation type of negative spatial autocorrelation.

Because the time interval of the data is from 2006 to 2016, this study draws Moran's I scatter plots for 2006, 2010, 2014, and 2017 at three-year intervals, as shown in Figures 3-6. The spatial agglomeration and distribution of China's regional innovation capabilities is stable. Most of them are located in the third quadrant (LL). Only 3-4 provinces are stable in the first quadrant $(\mathrm{HH})$. This indicates that the ratio of strong and weak provinces makes China's innovation ability stable. Innovative development has not made significant progress.

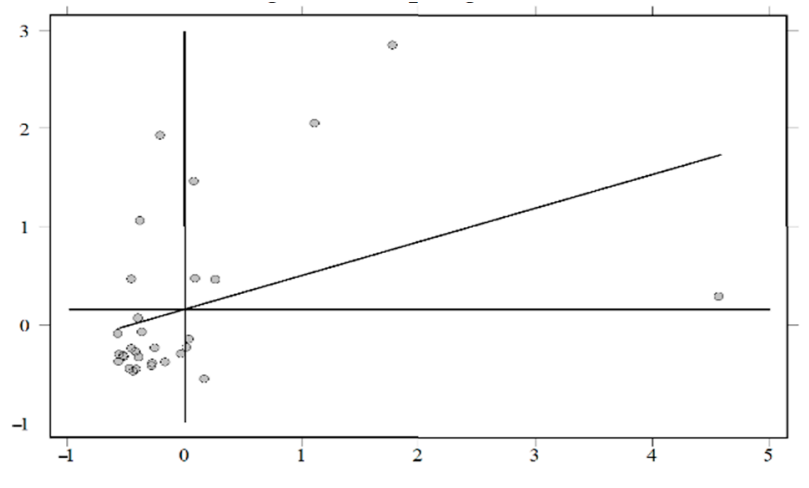

Figure 3. 2006 Moran scatter plot.

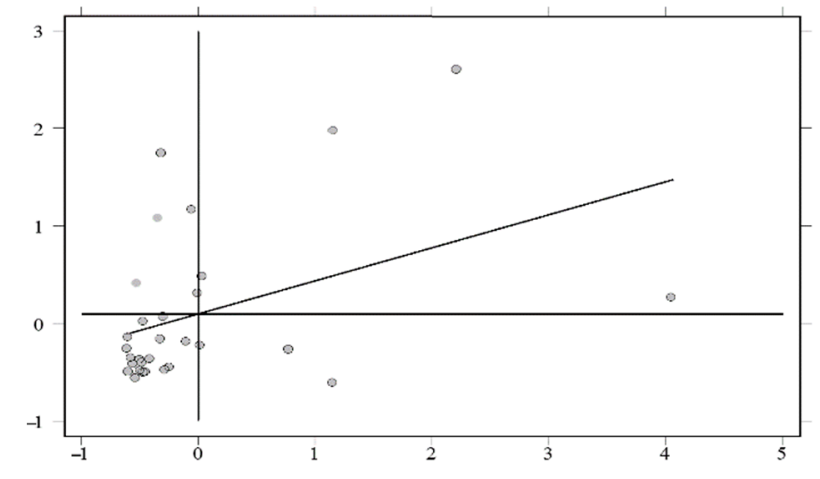

Figure 4. 2010 Moran scatter plot. 


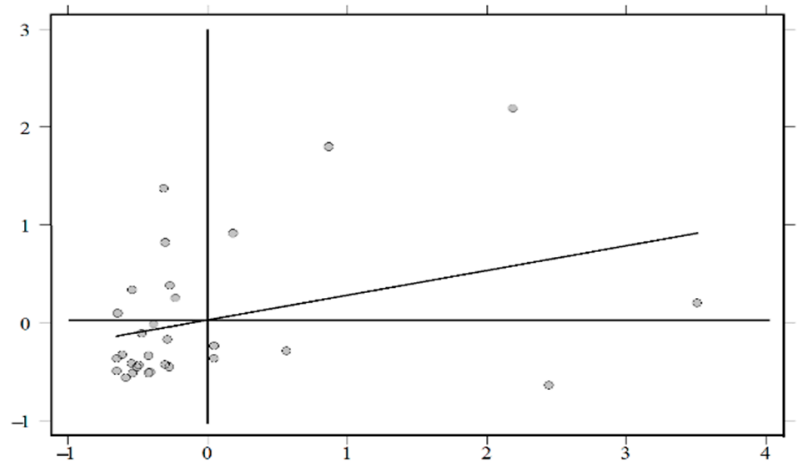

Figure 5. 2014 Moran scatter plot.

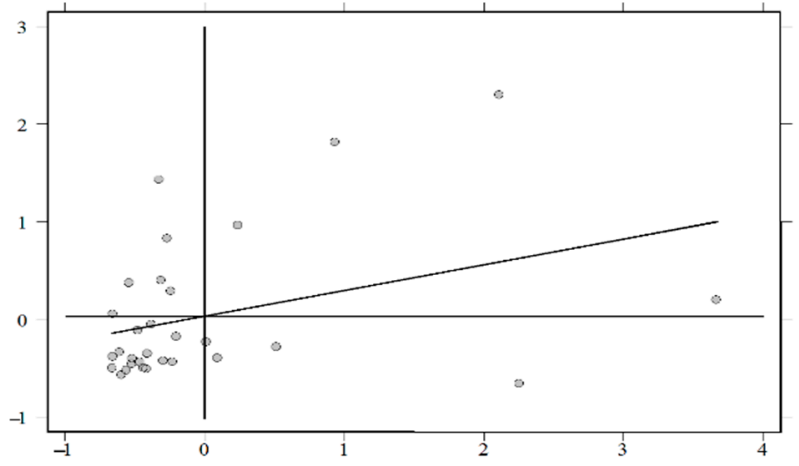

Figure 6. 2017 Moran scatter plot.

\subsection{General Panel Effect Test}

Panel models have various forms. They can be generally divided into mixed regression models, fixed effect models, and random effects models. The special nature of the provincial panel data has led to related studies often using fixed-effect models. However, there are three forms of fixed-effect models: spatial fixed effects, time-fixed effects, and two-way fixed effects. The space-fixed effect holds that the space between individuals does not change over time. The time-fixed effect holds that spatial heterogeneity is caused by the particularities of different time periods and there is no difference between individuals in the same period. The two-way fixed effect integrates the characteristics of the above two. It considers that heterogeneity is related to individuals and time. So, is this study suitable for using a fixed-effect model? If so, what fixed-effect model should be used? In this section, the F-test, $\mathrm{BP}$ test, LR test, and Durbin-Wu-Hausman test were used to answer the above questions. Table 5 lists the results of each test and Figure 7 describes the entire judgment process.

Table 5. Test results of ordinary panel model.

\begin{tabular}{ccccc}
\hline Kind & F-Value & BP-Value & LR-Value & D-W-Hausman-Value \\
\cline { 1 - 4 } Level & & & & \\
\hline (1) & $392.86^{* * *}$ & $881.44^{* * *}$ & $833.71^{* * *}$ & - \\
(2) & - & - & - & $16.69^{* * *}$ \\
(3) & $392.86^{* * *} 3.90^{* * *}$ & - & - & -
\end{tabular}

$* * * * *$ and * indicate statistical significance at the $1 \%, 5 \%$, and $10 \%$ levels, respectively. The same is true below. In (3), the upper value represents the test result in the spatial fixed effect, and the lower value represents the test result in the time-fixed effect model. 
(1)

Judge Mixed Model or Fixed Effect Model

Use F test

Result: Rejecte original hypothesis Select Fixed Effect Model

(2)

Judge Mixed Model or Random Effect Model

$$
\text { Use BP test and LR }
$$

Result: Rejecte original hypothesis Select Random Effect Model

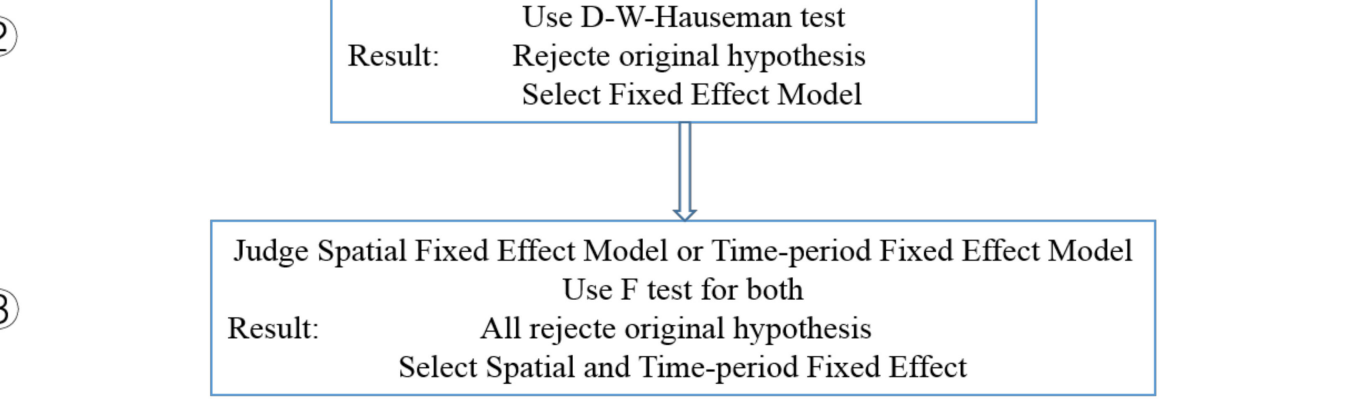

Figure 7. Derivation diagram of ordinary panel model.

\subsection{Spatial Panel Model Inspection}

The spatial Durbin model is a more commonly used spatial model. However, under certain conditions, it can be simplified into a spatial lag model or a spatial error model. In order to make the model more accurate and the empirical process more rigorous, this study tests whether the spatial model is better than the OLS model and whether the spatial Durbin model can be simplified through the LR test and the Wald test.

In the LR test, the LR values all passed the $1 \%$ significance test, and the null hypothesis was rejected. This indicates that the spatial model is better than the OLS model. In the Wald test, the Wald values also passed the $1 \%$ significance test. This indicates that SDM cannot be reduced to SLM or SEM. Therefore, the spatial Durbin model is the most suitable spatial model for this paper. Table 6 lists the specific results of the LR test and the Wald test.

Table 6. Results of LR test and Wald test.

\begin{tabular}{|c|c|c|c|}
\hline Hypothesis & LR-Value & Hypothesis & Wald-Value \\
\hline $\begin{array}{l}\text { Null hypothesis: SEM is not better } \\
\text { than OLS Model } \\
\text { Alternative hypothesis: SEM is } \\
\text { better than OLS Model }\end{array}$ & $86.1970 * * *$ & $\begin{array}{l}\text { Null hypothesis: SDM can be } \\
\text { simplified to SEM } \\
\text { Alternative hypothesis: SDM cannot } \\
\text { be simplified to SEM }\end{array}$ & $58.5727^{* * *}$ \\
\hline $\begin{array}{l}\text { Null hypothesis: SLM is not better } \\
\text { than OLS Model } \\
\text { Alternative hypothesis: SLM is } \\
\text { better than OLS Model }\end{array}$ & $61.5252 * * *$ & $\begin{array}{c}\text { Null hypothesis: SDM can be } \\
\text { simplified to SLM } \\
\text { Alternative hypothesis: SDM cannot } \\
\text { be simplified to SLM }\end{array}$ & $109.2684^{* * *}$ \\
\hline
\end{tabular}

\section{Spatial Econometrics Analysis}

\subsection{Estimated Results of the Spatial Econometric Model}

This paper is based on the annual panel data of 30 provinces in China from 2006 to 2017 (excluding Hong Kong, the Macao and Taiwan regions, and the Tibet Autonomous Region). We used StataSE 15 to calculate the model of Equation (18) with the maximum likelihood estimation method. During the regression process of the spatial Durbin model, we found that the coefficients of $\mathrm{W} * \mathrm{~L} . \mathrm{P}, \mathrm{W} * \ln \mathrm{FDI}$, and $\mathrm{W} * \ln \mathrm{KS}$ were not significant (L.P represents the explanatory variable with a lag period). Therefore, we removed these three variables from $W * X$ by the "Durbin (variables)" command. The final regression results are shown in Table 7. However, Elhorst pointed out that the 
regression coefficients of the spatial Durbin model have no explanatory power and it is meaningless to discuss the value and significance of the coefficients. He emphasized that the coefficients should be decomposed into direct and indirect effects before the regression results should be explained [5]. Therefore, the empirical results in Table 7 are only used in the empirical test to further test the double-effect fixed-effect dynamic space. The Durbin model is the best choice in this paper. At the same time, the study decomposes the coefficients of the explanatory variables to obtain direct and indirect effects, as shown in Table 8.

Table 7. Comparison results of Spatial Durbin Model.

\begin{tabular}{|c|c|c|c|c|c|c|}
\hline \multirow[b]{2}{*}{$\begin{array}{l}\text { Independent } \\
\text { Variable }\end{array}$} & \multicolumn{4}{|c|}{ Spatial Durbin Model } & \multicolumn{2}{|c|}{ Ordinary Panel Model } \\
\hline & $\begin{array}{c}\text { Spatial } \\
\text { Fixed Effect }\end{array}$ & $\begin{array}{l}\text { Time-period } \\
\text { Fixed Effect }\end{array}$ & $\begin{array}{c}\text { S\&T Fixed } \\
\text { Effect }\end{array}$ & $\begin{array}{c}\text { S\&T Fixed } \\
\text { Effect }\end{array}$ & Pooled OLS & $\begin{array}{l}\text { S\&T Fixed } \\
\text { Effect }\end{array}$ \\
\hline $\mathrm{W}^{*} \mathrm{~K}$ & $\begin{array}{c}0.9468^{* * *} \\
(3.21)\end{array}$ & $\begin{array}{c}0.6174^{* * *} \\
(5.07)\end{array}$ & $\begin{array}{c}1.2169^{* * *} \\
(3.83)\end{array}$ & $\begin{array}{c}1.2644^{* * *} \\
(3.96)\end{array}$ & - & - \\
\hline $\mathrm{W}^{*} \mathrm{AB}$ & $\begin{array}{c}3.0622^{* * *} \\
(3.55)\end{array}$ & $\begin{array}{l}9.2484^{* * * *} \\
(3.17)\end{array}$ & $\begin{array}{c}2.3371^{* * * *} \\
(2.64)\end{array}$ & $\begin{array}{c}2.1374^{* *} \\
(2.41)\end{array}$ & - & - \\
\hline $\mathrm{W}^{*} \mathrm{ABKS}$ & $\begin{array}{c}-0.1867 * * * \\
(-3.52)\end{array}$ & $\begin{array}{c}-0.5643^{* * *} \\
(-3.15)\end{array}$ & $\begin{array}{c}-0.1436^{* * *} \\
(-2.64)\end{array}$ & $\begin{array}{c}-0.1356 \text { ** } \\
(-2.42)\end{array}$ & - & - \\
\hline Constant & - & - & - & - & $\begin{array}{c}-19.4905^{* * *} \\
(-27.44)\end{array}$ & $\begin{array}{l}10.2073 \\
(-0.95)\end{array}$ \\
\hline$R^{2}$ & 0.8123 & 0.6448 & 0.8099 & 0.8083 & 0.5781 & 0.7368 \\
\hline Spat-rho & $\begin{array}{l}-0.0937 \\
(-1.11)\end{array}$ & $\begin{array}{c}0.5268^{* * *} \\
-8.66\end{array}$ & $\begin{array}{c}-0.4085^{* * *} \\
(-4.44)\end{array}$ & $\begin{array}{c}-0.4077^{* * *} \\
(-4.41)\end{array}$ & - & - \\
\hline
\end{tabular}

$*^{* * *}$, and ${ }^{* * *}$ indicate statistical significance at the $10 \%, 5 \%$, and $1 \%$ levels, respectively. $Z$ statistics in parentheses.

Table 8. Direct and indirect effects in China.

\begin{tabular}{cccccccc}
\hline Direct Effect & Coefficient & Z-Value & $\boldsymbol{p}$-Value & Indirect Effect & Coefficient & Z-Value & $p$-Value \\
\hline L1.p & -0.0171 & -1.86 & 0.062 & L1.p & 0.0053 & 1.75 & 0.08 \\
K & 0.357 & 2.97 & 0.003 & K & 0.8241 & 3.24 & 0.001 \\
KS & -0.4871 & -1.42 & 0.155 & KS & 0.1531 & 1.32 & 0.187 \\
AB & -0.4162 & -1.08 & 0.282 & AB & 1.9066 & 2.79 & 0.005 \\
FDI & 0.056 & 2.07 & 0.039 & FDI & -0.0174 & -1.83 & 0.067 \\
ABKS & 0.0275 & 1.15 & 0.249 & ABKS & -0.1176 & -2.8 & 0.005 \\
\hline
\end{tabular}

By comparing $R^{2}$, Spat-rho and $\mathrm{W}^{*} \mathrm{X}$ items, from Table 7 , we decided that the dynamic spatial Durbin model with two-way fixed effects is the optimal choice.

An analysis of Table 8 revealed that the direct effect coefficient of the interaction term of absorptive capacity and knowledge spillover (ABKS) is 0.0275 , and the $p$-value is 0.249 , which is not significant. However, the coefficient of its indirect effect is -0.1176 , and the $p$-value is 0.005 , which is significant. (In Section 3.4, this paper uses the economic distance matrix to measure the knowledge spillover index. The greater the economic distance, the smaller the level of knowledge spillover. Therefore, the direct effect containing the variable KS is similar to the "indirect effect" on economic distance. In the indirect effect, the priority of the first-order adjacency matrix is higher than the economic distance matrix. Therefore, the indirect effect still reflects the spillover effect of a province on neighboring provinces.) This shows that absorptive capacity has an inhibiting effect on the innovation capacity of neighboring provinces ( $\mathrm{H} 1$ is correct). At the same time, the greater the economic distance between the two provinces, the stronger the promotion effect of absorptive capacity, but this effect is not significant (H2 is not correct). According to the actual situation in China, the possible reasons are as follows: First, the absorptive capacity of provinces with strong economic levels (such as eastern China, which accounts for half of the Chinese economy) is already at a high level. Moreover, it has moved away from the stage of simple imitation and learning, and continued to improve the level of absorptive capacity and knowledge spillovers, which has inhibited the development of innovation. For example, there is a 
"siphon effect" on areas with weak economic levels, or spillover knowledge cannot be absorbed and used because of the large technological gap. The direct effects of KS and AB (both signs are negative and insignificant) also confirm this. Second, there is a "double threshold" characteristic of absorption capacity, showing an "inverted U-shape" characteristic. China has experienced rapid development in reform and opening-up for decades. The overall level of absorptive capacity has reached a high level, approaching the apex of an "inverted U-shape." The benefits of improving absorptive capacity are less than the cost of upgrading. Third, according to the definition of absorptive capacity in this study, regions with higher absorptive capacity have more talent and are more likely to attract a further influx of talent. This often leads to problems such as a lack of talent in neighboring provinces, which restricts their innovation and development. For example, if Zhejiang and Guangdong implement a talent introduction policy, it will inevitably cause a decrease in the number of talented individuals moving into Fujian.

\subsection{Regional Tests}

There are large differences in the economy, culture, environment, and policies of China's eastern, central, and western regions. (According to the Fifth Session of the Eighth National People's Congress of China, China is divided into eastern regions (Beijing, Tianjin, Hebei, Liaoning, Shanghai, Jiangsu, Zhejiang, Fujian, Shandong, Guangdong, and Hainan), central regions (Shanxi, Jilin, Heilongjiang, Anhui, Jiangxi, Henan, Hubei, and Hunan), and western regions (Sichuan, Chongqing, Guizhou, Yunnan, Tibet, Shaanxi, Gansu, Qinghai, Ningxia, Xinjiang, Guangxi, and Inner Mongolia).) Furthermore, we need to make the empirical results more convincing and to explore the role of absorptive capacity, enhance knowledge spillovers, and thus enhance innovation. Consequently, this study conducted the abovementioned empirical tests in the eastern, central, and western regions of China. The results are shown in Table 9. Figure 8 shows the distribution of eastern, central, and western China.

Table 9. Direct and indirect effects of ABKS in different regions.

\begin{tabular}{cccccc}
\hline & Direct Effect & Indirect Effect & $\boldsymbol{R}^{\mathbf{2}}$ & Spat-rho & Log-L \\
\hline Eastern region & $0.0075(0.26)$ & $-0.0501(-1.41)$ & 0.8589 & $-0.2722^{* * *}(-3.15)$ & 45.8746 \\
Central region & $0.0135(0.36)$ & $-0.1417^{* *}(-2.32)$ & 0.7356 & $-0.1351^{*}(-1.72)$ & 19.4872 \\
Western region & $0.0562(1.37)$ & $-0.1674^{*}(-1.83)$ & 0.8172 & $-0.3394^{* *}(-2.37)$ & -66.2759 \\
\hline
\end{tabular}

$* * *$, and ${ }^{* * *}$ indicate statistical significance at the $10 \%, 5 \%$, and $1 \%$ levels, respectively. $Z$ statistics in parentheses.

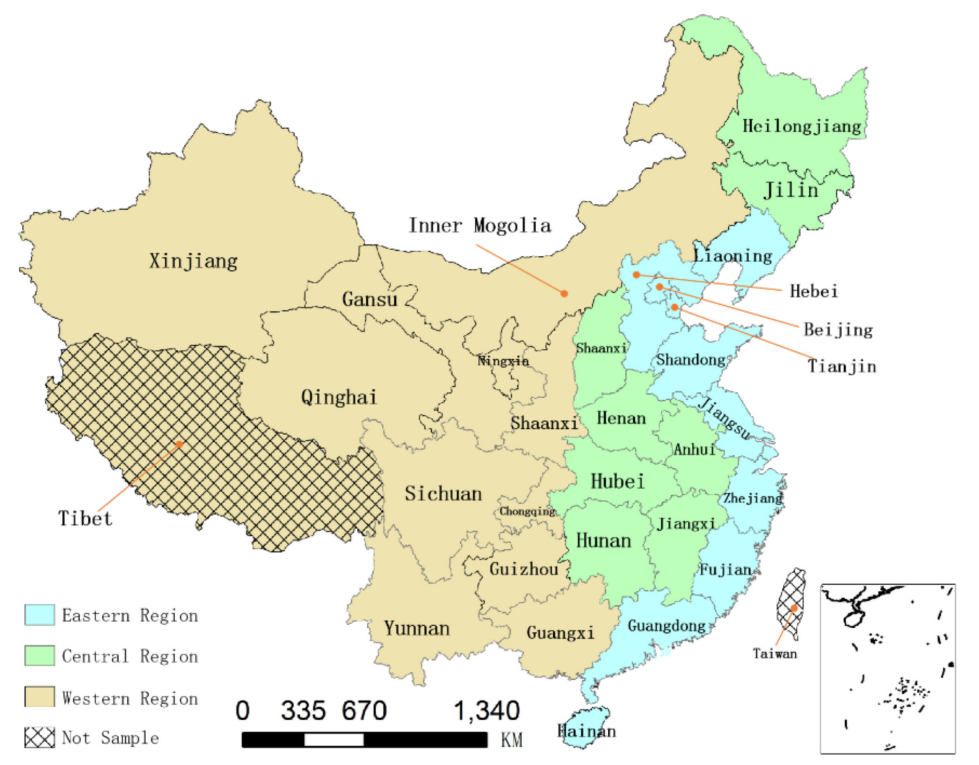

Figure 8. Distribution in eastern, central and western China. 
According to Table 9, the direct effect coefficients of ABKS are all positive, but not significant. Of the indirect effects, the coefficients of all regions are negative, but only the central and western regions have passed the significance test. (1) The direct effects of the three subregions are not significant, which is the same as the conclusions in Table 9. (2) Different from the conclusions in Table 9, the indirect effect coefficient of the eastern region is not significant. This is due to the higher level of innovation in the eastern provinces and the departure from the innovation and promotion mechanism that relies on imitation, which greatly reduces the effect of spillover effects. 3) The result of indirect effects in the central and western regions is the same as the conclusions in Table 9.

\subsection{Robustness Test}

In order to ensure the robustness of the conclusion, we will further use the freight railway distance matrix to replace the economic distance matrix and construct a new knowledge spillover index in the spatial econometric model. The results are shown in Table 10.

Table 10. Results of robust test.

\begin{tabular}{cccccccc}
\hline Direct Effect & Coefficient & Z-Value & $p$-Value & Indirect Effect & Coefficient & Z-Value & $p$-Value \\
\hline L1.p & -0.0103 & -1.16 & 0.246 & L1.p & 0.0029 & 1.11 & 0.268 \\
K & 0.1633 & 1.32 & 0.187 & K & 1.4722 & 4.97 & 0.000 \\
KS & -1.8908 & -4.82 & 0.000 & KS & 0.5432 & 3.48 & 0.001 \\
AB & -0.4764 & -1.22 & 0.222 & AB & 1.2349 & 1.89 & 0.059 \\
FDI & 0.0856 & 3.23 & 0.001 & FDI & -0.0248 & -2.51 & 0.012 \\
ABKS & 0.0308 & 1.3 & 0.195 & ABKS & -0.0762 & -1.92 & 0.055 \\
\hline
\end{tabular}

It can be seen from Table 10 that in terms of direct effects and indirect effects, the signs of the coefficients of the variables are the same, the sizes are the same, and the significant conditions are about the same. The direct effect of the ABKS term is not significant, but its indirect effect is more significant. On the whole, the empirical results are consistent with the previous ones, indicating that the previous conclusions are robust.

\section{Conclusions}

\subsection{Concluding Remarks}

Based on the annual panel data of 30 provinces in China from 2006 to 2017, this paper constructs a seven-dimensional absorptive capacity index evaluation system. We use the entropy weight method to measure its score. We explore the spatial relationship between the promotion effect of absorptive capacity on knowledge spillovers and regional innovation capacity through spatial measurement methods. First, this paper shows that there is a clear positive spatial autocorrelation in regional innovation capacity (as measured by the number of patent grants). Moreover, $80 \%$ of provinces exhibit low-low agglomeration (LL) characteristics throughout the year. Fewer than $20 \%$ of provinces exhibit high-agglomeration $(\mathrm{HH})$ characteristics. This is because China's "common prosperity" policy encourages the development of some regions (mainly the eastern region). Namely, it allows some people to get rich first, but drives other regions to achieve common prosperity. Thirty years after the implementation of the policy, with the support of the Chinese government, the eastern region has rapidly increased and developed rapidly. It has also played a positive role in the development of the central and western regions. However, development takes time. Until 2019, the central and western regions of China were still significantly weaker than the eastern regions, thus contributing to HH-LL differentiation. Secondly, at the national level, the promotion effect of absorptive capacity in one province on knowledge spillovers has no obvious effect on innovation promotion in other provinces, especially in provinces with similar economic levels. This will inhibit the innovation development of neighboring provinces. Finally, by studying the eastern, central, and western regions 
of China, we find that the role of absorptive capacity in promoting knowledge spillover varies from region to region. The eastern provinces will not be adversely affected by the development of absorptive capacity of neighboring provinces. The results in the central and western regions are not substantially different from the full sample study. This is due to the high level of innovation in the eastern provinces, which is separate from the innovation promotion mechanism that relies on imitation. This greatly reduces spillover effects. Furthermore, there is more talent concentrated in the eastern region. Consequently, increasing the absorption capacity of one province will not cause a talent shortage in neighboring provinces, while the central and western regions are dominated by basic industries. There are fewer exchanges and cooperation, lower inter-industry linkages, and thus lower matching of spilled external knowledge.

\subsection{Theoretical and Policy Implications}

First, we must firmly adhere to the principle of "common prosperity," and the "rich first, rich later, common prosperity" concept. We are bound to find and seize the opportunity. We should also formulate corresponding policies to support subsidies so as to achieve economic prosperity in central and western regions. At the same time, we must always grasp the scientific development concept and the sustainable development concept. We should take eastern development as an example to realize the harmonious coexistence and common development of man and nature in modernization.

Second, we need to build an innovation platform. We should promote the cooperation between local governments, scientific research institutions, and universities. At the same time as optimizing the allocation of innovation resources, through the government bridge, we should encourage talent across the country to break the space constraints on innovative talent and train up more talented individuals.

Third, we must optimize the talent training mechanism and increase the treatment for talent introduction. Human capital is the fundamental element of innovation. By encouraging the cultivation of innovative and research talents, we should provide more support and convenience for the education of master's and doctoral students. In this way, we strive to cultivate China's own outstanding talent. At the same time, we will increase talent introduction. That is to say, we not only need to prevent talent from flowing abroad, but must continue to inject new blood into the domestic market in terms of innovation. In this way, we can maintain the green, healthy, and sustainable development of China.

Fourth, we must promote the reform of state-owned enterprises and improve the competitiveness of the state-owned economy. State-owned enterprises face conflicts of demands for "profitable missions" and "public policy use" in the process of production and operation. They have the problems of redundant structures, a lack of incentives, poor management, and sustained losses. These are not conducive to the effective allocation and utilization of resources. In this case, state-owned enterprise reform is imperative. On the one hand, the privatization of state-owned enterprises makes them participate in market competition. This will force them to improve their competitiveness, optimize management structure, operate rationally, and increase profits. On the other hand, they should clarify their positioning and focus the state-owned capital on industries that are important to the national economy. The government should reduce its intervention in the market and allow "invisible hands" to regulate market resources.

\subsection{Limitations and Guidelines for Future Research}

First, limited by the data, there is still room for improvement of the absorptive capacity index constructed in this paper.

Second, due to the lack of corresponding data, the paper only uses FDI as a control variable to mitigate the impact of foreign countries, but the impact cannot be eradicated.

Third, the paper has done research on the national level, and at the eastern, central and western regions level. Researchers who are interested in a particular area can try to analyze it from the perspective of a city group level or prefecture-level city. 
Author Contributions: Conceptualization, Y.T.; Data curation, H.X.; Formal analysis, H.X.; Funding acquisition, Y.T.; Methodology, Y.T.; Software, Y.C. and K.W.; Writing-review and editing, K.W., Y.C. and X.Y. All authors have read and agreed to the published version of the manuscript.

Funding: This research was funded by the National Natural Science Foundation of China (No. 71072066), Sichuan University (No. SKGT201602, No. 2018HHF-42), and the Department of Science and Technology of Sichuan Province (No. 2018JY0594).

Conflicts of Interest: The authors declare that they have no conflicts of interest.

\section{References}

1. Batabyal, A.A.; Nijkamp, P. Positive and negative externalities in innovation, trade, and regional economic growth. Geogr. Anal. 2014, 46,1-17. [CrossRef]

2. Zhao, S.; Jiang, Y.; Wang, S. Innovation stages, knowledge spillover, and green economy development: Moderating role of absorptive capacity and environmental regulation. Environ. Sci. Pollut. Res. 2019, 26, 25312-25325. [CrossRef] [PubMed]

3. Nieto, M.; Quevedo, P. Absorptive capacity, technological opportunity, knowledge spillovers, and innovative effort. Technovation 2005, 25, 1141-1157. [CrossRef]

4. Egbetokun, A.; Savin, I. Absorptive Capacity and Innovation: When is It Better to Cooperate. In The Evolution of Economic and Innovation Systems; Springer: Cham, Switzerland, 2015; pp. 373-399.

5. Elhorst, J.P. Matlab software for spatial panels. Int. Reg. Sci. Rev. 2014, 37, 389-405. [CrossRef]

6. Kedia, B.L.; Bhagat, R.S. Cultural constraints on transfer of technology across nations: Implications for research in international and comparative management. Acad. Manag. Rev. 1988, 13, 559-571. [CrossRef]

7. Cohen, W.M.; Levinthal, D.A. Absorptive capacity: A new perspective on learning and innovation. Adm. Sci. Q. 1990, 35, 128-152. [CrossRef]

8. Chen, J.; Chen, Y.F.; Yu, F.Z. The impact of FDI on regional innovation capability. Sci. Res. Manag. 2007, 7-13. [CrossRef]

9. Lau, A.K.; Lo, W. Absorptive capacity, technological innovation capability and innovation performance: An empirical study in Hong Kong. Int. J. Technol. Manag. 2019, 80, 107-148. [CrossRef]

10. Weng, H.H.R.; Chen, J.S.; Chen, P.C. Effects of green innovation on environmental and corporate performance: A stakeholder perspective. Sustainability 2015, 7, 4997-5026. [CrossRef]

11. Li, Y.; Tang, Y.; Wang, K.; Zhao, Q. Environmental Regulation and China's Regional Innovation Output_Empirical Research Based on Spatial Durbin Model. Sustainability 2019, 11, 5602. [CrossRef]

12. Zhang, J.T.; Chen, L. Evaluation on China's Regional Independent Innovation Capacity by Using Factor and Cluster Analysis-Innovation System Respective. J. Ind. Technol. Econ. 2011, 30, 36-44. [CrossRef]

13. Ibrahim, S.E.; Fallah, M.H.; Reilly, R.R. Localized sources of knowledge and the effect of knowledge spillovers: An empirical study of inventors in the telecommunications industry. J. Econ. Geogr. 2009, 9, 405-431. [CrossRef]

14. Griliches, Z. Issues in assessing the contribution of research and development to productivity growth. Bell J. Econ. 1979, 10, 92-116. [CrossRef]

15. Arrow, K.J. The Economic Implications of Learning by Doing. In Readings in the Theory of Growth; Palgrave Macmillan: London, UK, 1971; pp. 131-149.

16. Romer, P.M. Increasing returns and long-run growth. J. Polit. Econ. 1986, 94, 1002-1037. [CrossRef]

17. Romer, P.M. Endogenous technological change. J. Polit. Econ. 1990, 98, S71-S102. [CrossRef]

18. Bottazzi, L.; Peri, G. Innovation and spillovers in regions: Evidence from European patent data. Eur. Econ. Rev. 2003, 47, 687-710. [CrossRef]

19. Breschi, S.; Lissoni, F. Knowledge spillovers and local innovation systems: A critical survey. Ind. Corp. Chang. 2001, 10, 975-1005. [CrossRef]

20. Guo, J.Y.; Zhang, Q.L. Provincial Knowledge Spillovers and the Agglomeration of Regional Innovation Activities-Analysis Based on the Spatial Econometrics Method. RED Manag. 2012, 24. [CrossRef]

21. Jaffe, A.B. Real effects of academic research. Am. Econ. Rev. 1989, 79, 957-970.

22. Audretsch, D.B.; Feldman, M.P. R\&D spillovers and the geography of innovation and production. Am. Econ. Rev. 1996, 86, 630-640. 
23. Audretsch, D.B.; Feldman, M.P. Knowledge Spillovers and the Geography of Innovation. In Handbook of Regional and Urban Economics; Elsevier: Amsterdam, The Netherlands, 2004; Volume 4, pp. 2713-2739.

24. Cooke, P. Regional innovation systems: Development opportunities from the 'green turn'. Technol. Anal. Strateg. Manag. 2010, 22, 831-844. [CrossRef]

25. Szulanski, G. Exploring internal stickiness: Impediments to the transfer of best practice within the firm. Strateg. Manag. J. 1996, 17 (Suppl. S2), 27-43. [CrossRef]

26. Chen, X.H.; Song, Y. The Appraisement and Comparison of Knowledge Absorptive Capacity of Regional Innovation System-Based on Sample Data of Chinese 31 Provincial Regions. Sci. Technol. Prog. Policy 2011, 28, 108-112. [CrossRef]

27. Tura, T.; Harmaakorpi, V. Social capital in building regional innovative capability. Reg. Stud. 2005, 39, 1111-1125. [CrossRef]

28. Hauser, C.; Tappeiner, G.; Walde, J. The learning region: The impact of social capital and weak ties on innovation. Reg. Stud. 2007, 41, 75-88. [CrossRef]

29. Braunerhjelm, P.; Ding, D.; Thulin, P. The knowledge spillover theory of intrapreneurship. Small Bus. Econ. 2018, 51, 1-30. [CrossRef]

30. Wang, C.F. Moderating Effects about Knowledge Spillover and Regional Innovation Efficiency. China Popul. Resour. Environ. 2015, 25, 77-83. [CrossRef]

31. Agrawal, A.; McHale, J.; Oettl, A. Does Scientist Immigration Harm US Science? An Examination of Spillovers (No. w24519). Natl. Bur. Econ. Res. 2018. [CrossRef]

32. Hájek, P.; Stejskal, J. R\&D cooperation and knowledge spillover effects for sustainable business innovation in the chemical industry. Sustainability 2018, 10, 1064.

33. Asplund, C.J.; Bengtsson, L. Knowledge spillover from Master of Science Theses in Engineering Education in Sweden. Eur. J. Eng. Educ. 2019. [CrossRef]

34. Zhai, Y.M.; Sun, W.Q.; Tsai, S.B.; Wang, Z.; Zhao, Y.; Chen, Q. An empirical study on entrepreneurial orientation, absorptive capacity, and SMEs' innovation performance: A sustainable perspective. Sustainability 2018, 10, 314. [CrossRef]

35. Zhang, Y.; Zhao, F.S. Research on the Impact of International Technology Spillover and Absorptive Capacity on Independent Innovation of High-tech Industry. J. Financ. Econ. 2017, 43, 94-106. [CrossRef]

36. Zhang, X.L.; Lv, G.Q.; Jia, L. Technology Introduction, Technological Absorptive Capacity and Innovation Performance-Based on Data from Shanghai Agricultural Enterprises. J. Agrotech. Econ. 2018, 80-87. [CrossRef]

37. Ma, R. The Effect of Social Capital on Regional Innovation in China-A Perspective of Spatial Knowledge Spillover. Soft Sci. 2017, 31, 29-32. [CrossRef]

38. Zhu, J.J.; Xu, C.H. The Threshold of the Regional Innovation Performance Improvement Effect-Based on the Perspective of Absorptive Capacity. Financ. Econ. 2017, 11, 116-128.

39. Wei, S.H.; Gu, J.J.; Jiang, Y. Literature Review on Knowledge Spillover, Absorptive Capacity and Economic Performance. Modern Econ. Res. 2017, 123-132. [CrossRef]

40. Kang, W.; Zhao, S.; Song, W.; Zhuang, T. Triple helix in the science and technology innovation centers of China from the perspective of mutual information: A comparative study between Beijing and Shanghai. Scientometrics 2019, 118, 921-940. [CrossRef]

41. Wang, L.F.; Hu, Y. Does Venture Capital Improve Innovation Efficiency? Evidence from China's Firm-level Analysis. J. Financ. Res. 2017, 1, 13.

42. Zhao, Y.; Bi, C. An Agent-Based Simulation Model of Knowledge Spillover under the Influence of High-Speed Railway. J. Syst. Sci. Inf. 2019, 7, 99-114. [CrossRef]

43. Xu, H.; Shi, X.L.; Wang, K. The Influence of Absorptive Capacity on Regional Innovation-An Empirical Research Based on Knowledge Spillovers. J. Jimei Univ. 2018, 21, 49-55. [CrossRef]

44. Goto, A.; Suzuki, K. R \& D capital, rate of return on R \& D investment and spillover of R \& D in Japanese manufacturing industries. Rev. Econ. Stat. 1989, 71, 555-564.

45. Li, J.; He, Y.L. Evaluations of Knowledge Spillovers Based on Space-related Regional Innovation Systems. Sci. Technol. Manag. Res. 2016, 58-66. [CrossRef]

46. Guan, J.; Ma, N. Innovative capability and export performance of Chinese firms. Technovation 2003, 23, 737-747. [CrossRef] 
47. Archibugi, D.; Pianta, M. Innovation Surveys and Patents as Technology Indicators: The State of the Art. Available online: http://hdl.handle.net/11576/1889690 (accessed on 12 March 1996).

48. Archambault, É. Methods for using patents in cross-country comparisons. Scientometrics 2002, 54, 15-30. [CrossRef]

49. Jaffe, A.B.; Trajtenberg, M.; Henderson, R. Geographic localization of knowledge spillovers as evidenced by patent citations. Q. J. Econ. 1993, 108, 577-598. [CrossRef]

50. Chen, C. Import Trade, FDI and International Intellectual Capital Spillover-Empirical Analysis from Multinational Panel Data. World Econ. Study 2016, 90-100. [CrossRef]

51. Tobler, W.R. A computer movie simulating urban growth in the Detroit region. Econ. Geogr. 1970, 46 (Suppl. 1), 234-240. [CrossRef]

(C) 2020 by the authors. Licensee MDPI, Basel, Switzerland. This article is an open access article distributed under the terms and conditions of the Creative Commons Attribution (CC BY) license (http://creativecommons.org/licenses/by/4.0/). 